\section{$\underset{\text { \&ommes migrations }}{\text { hommes }}$}

\section{Hommes \& migrations}

Revue française de référence sur les dynamiques

migratoires

\section{1 | 2011}

Diasporas sri lankaises

\title{
Les Tamouls en Europe
}

\section{Marie Poinsot}

\section{(2) OpenEdition \\ Journals}

\section{Édition électronique}

URL : http://journals.openedition.org/hommesmigrations/664

DOI : 10.4000/hommesmigrations.664

ISSN : 2262-3353

\section{Éditeur}

Musée national de l'histoire de l'immigration

\section{Édition imprimée}

Date de publication : 1 mai 2011

Pagination : 1

ISSN : 1142-852X

\section{Référence électronique}

Marie Poinsot, "Les Tamouls en Europe », Hommes \& migrations [En ligne], 1291 | 2011, mis en ligne le 29 mai 2013, consulté le 22 septembre 2020. URL : http://journals.openedition.org/

hommesmigrations/664 ; DOl : https://doi.org/10.4000/hommesmigrations.664 


\section{Les Tamouls en Europe Par Marie Poinsot, rédactrice en chef}

La revue Hommes \& Migrations regrette l'annulation d'un dossier portant sur les "traces postcoloniales en France" dont la coordination était assurée par Esther Benbassa, directrice d'études à l'École pratique des hautes études et du Centre Alberto-Benveniste. Cette non-parution en mai dernier entraîne des changements notables dans la programmation éditoriale de 2012, du retard dans la livraison des prochains numéros, retard que la rédaction va s'attacher à rattraper dans les mois à venir.

L'équipe, désolée de cette situation imprévue, vous remercie de votre compréhension.

Sri Lanka était depuis longtemps une terre d'immigration en vertu de sa situation de carrefour dans l'océan Indien. Dès la fin des années cinquante, l'île est devenue un pays d'émigration, dans un premier temps dans le sillage de la décolonisation britannique, et vers le Moyen-Orient. La guerre civile opposant la minorité tamoule à la population majoritaire cinghalaise a ravagé le pays pendant les trois dernières décennies. Elle a provoqué le départ d'une diaspora sri lankaise majoritairement tamoule et très active politiquement, qui ne se cantonne plus aux pays du Commonwealth, mais se déploie dans toute l'Europe. Aujourd'hui, forte d'environ un million de personnes, elle prend racine dans différents pays européens avec une visibilité variable selon les modalités d'installation dans les sociétés d'accueil. Or, jusqu'à très récemment, cette migration restait peu connue, faute de travaux de recherches suffisamment diffusés, alimentant une stigmatisation croissante dans les discours publics de certains pays européens.

Voici un dossier qui fera date dans le petit monde des revues. Anthony Goreau-Ponceaud, jeune maître de conférences de l'université de Bordeaux, a pu mobiliser tout un réseau de chercheurs en France et à l'étranger pour rassembler des articles sur les diasporas sri lankaises dont l'ampleur a surpris, même le milieu scientifique, dont les travaux n'ont démarré en France qu'à la fin des années quatre-vingt-dix.

L'approche comparative adoptée dans ce dossier révèle l'incroyable diversité et la complexité de cette migration, non seulement en termes de pluralité linguistique et religieuse, mais aussi en termes de dynamiques sociologiques et économiques. La dimension transnationale, propre aux migrations diasporiques, se singularise ici par la recomposition d'une identité forgée par l'exil et le conflit, aujourd'hui confrontée au retour de la paix à Sri Lanka. Les Tigres de libération de l'Eelam tamoul (LTTE) et leurs réseaux associatifs, véritables leviers politiques de ces diasporas à l'étranger sur la base de revendications indépendantistes, sont dorénavant placés dans une position ambivalente entre le maintien d'une mémoire réifiée qui structure les communautés et la volonté d'ouverture des jeunes générations dans les sociétés européennes.

La revue remercie Vasantha Yogananthan pour la qualité de son reportage sur les Tamouls en région parisienne. Plus que des illustrations d'articles, ses photos témoignent de la constitution d'un patrimoine culturel et identitaire à partir des événements qui mettent en scène l'histoire des Tamouls à Sri Lanka. 